\title{
Analysis on Physical and Mechanical Properties of Red Mud Materials and Stockpile Stability after Dilatation
}

\author{
Yanbo Feng (iD) and Chao Yang $\mathbb{D D}^{2}$ \\ ${ }^{1}$ School of Civil \& Architecture Engineering, Chongqing University of Arts and Sciences, Chongqing 402160, China \\ ${ }^{2}$ Key Laboratory of Geological Hazards on Three Gorges Reservoir Area, Ministry of Education (China Three Gorges University), \\ Yichang, Hubei 443002, China \\ Correspondence should be addressed to Chao Yang; vanni1010@aliyun.com
}

Received 10 January 2018; Revised 6 March 2018; Accepted 22 April 2018; Published 21 May 2018

Academic Editor: Federica Bondioli

Copyright (c) 2018 Yanbo Feng and Chao Yang. This is an open access article distributed under the Creative Commons Attribution License, which permits unrestricted use, distribution, and reproduction in any medium, provided the original work is properly cited.

Red mud is the tailings generated from the production process of aluminum industry and is mainly stacked in open-air at present, so how to ensure the stability of red mud stockpile is very important. Regarding mud stockpile of Guizhou Aluminum Factory as the research object, this paper studies the physical and mechanical properties of Bayer red mud from wetting process, Bayer red mud from drying process, and sintering red mud through laboratory test and finally analyzes its stability under extreme rainfall condition in this region by the Geo-Studio software. The research results show that the red muds in different processes have big difference in physical and mechanical properties. The strength of sintering red mud is about 4.2 times of that of Bayer red mud from wetting process on average, and the strength of Bayer red mud from drying process is about 1.5 times of that of Bayer red mud from wetting process on average. So, the sintering red mud can be used as the subdam of red mud stockpile, to reduce the risk of collapse and dam break. The stability coefficients of the mixed stocking method under three rainfall conditions are 2.611, 2.597, and 2.631, respectively, all of which are above 1.0. It reveals that the dilatation scheme of using the sintering red mud with good engineering properties to stockpile the Bayer red mud is feasible. It can not only guarantee the safety and stability of red mud stockpiles, but also reduce the risk of red mud dam break and the capital investment of red mud yard.

\section{Introduction}

Red mud is the tailings generated from the production process of alumina in aluminum industry. With rapid growth of aluminum output in recent years, the discharge amount of red mud increases accordingly. About 120,000,000 t red mud would be discharged globally every year [1]. In China, the discharge amount of red mud in several alumina production bases (involving Chalco Guizhou branch, Chalco Shandong branch, and Chalco Henan branch) is up to 50,000,000 t every year [2]. The red mud contains much aluminum and iron and also contains rare metals such as scandium, titanium, and vanadium. Thus, the resource utilization of red mud attracts the universal attention and comparatively deep research, and achievements have been made, such as extraction of valuable metal, and preparation of building materials or adsorbing materials [3-5]. However, these applications cannot achieve industrial-scale production; due to small amount of actual consumption but very high disposal cost of red mud (accounting for about $5 \%$ of alumina production cost) [6], stockpiling it in an open yard is still the first choice for the treatment of red mud. Moreover, as the land restriction policies and land price in China have risen sharply in recent years, it is impossible to build new tailing reservoir, and the newly generated red mud can still only be stacked on the original stockpiles. Obviously, with the further increase of stockpiling quantity, how to ensure the stability of red mud stockpile is very important. Once the leakage of leachate or red mud dam break happens, the surrounding environment will be seriously influenced.

The red mud produced from different processes has big difference in respect of appearance and microstructure, so that different red muds have their physical and mechanical properties [7]. At present, the alumina production processes in China mainly include Bayer process and sintering process. Bayer process is a process of extracting the alumina from the 
bauxite invented by the Austrian chemist Bayer between 1889 and 1892, and its tailing is Bayer red mud [8]. Bayer red mud has fine particles, engineering properties similar to silty clay, high water content, poor permeability, low shear strength, and long consolidation time [9]. The sintering process mainly uses soda lime to sinter the raw materials involving bauxite, nepheline, and Bayer red mud, and its tailing is sintering red mud. Compare to Bayer red mud, the sintering red mud has coarser particles and higher sand content and is consolidated and hardened through filtering process during stockpiling with high strength [9]. Various alumina factories in China discharge the red mud by "wetting process" at the initial production stage, that is, the liquid red mud with high water content is discharged into the red mud yard directly by the pipeline, and stacked at the bottom of red mud reservoir, to form a weak layer with big thickness and low strength. However, with the increase of red mud discharge amount, in order to utilize the existing reservoir effectively and expand the reservoir capacity, now the red mud is pressed and filtered by the pressure filter to a certain water content and then conveyed to the red mud yard by the belt conveyor for stockpiling, that is, "drying process" stockpiling.

With further development of industrialization, the stability of industrial waste tailings reservoir nowadays draws more and more attention from the academic and engineering sectors. For example, Chandler and Tosatti [10] sorted out and analyzed the causes and losses of Italy Stava tailing dam break and put forward some valuable preventive measures. Moxon [11], Whitlow and Richard [12], and Strachan [13] researched the causes of gold ore tailing dam break in Spain, Zambia, and America and presented some postbreak remedy methods, whereas, the studies on the red mud tailing reservoir are few at present, especially in respect of stockpile stability. It is well known that, rainfall is an important factor for the slope instability [14-16]. For the red mud stockpile, its permeability is relatively poor, and the rain wash and infiltration increase the internal water pressure of stockpile, which has great influence on the stability of red mud stockpile.

Guizhou Aluminum Factory adopts the "wetting process" to stack the Bayer red mud for 40 years since putting into production, and the reservoir capacity fails to meet the requirements. How to increase the reservoir capacity of the original yard is extremely urgent. In this paper, the physical, microscopic, mechanical, and hydraulic characteristic parameters of red mud in this yard are obtained through the laboratory test, the design scheme of yard dilatation is put forward based on relevant experience of similar engineering, and finally the stockpile stability after dilatation under different rainfall conditions is calculated and analyzed. The conclusion can provide some reference for design and construction of similar engineering.

\section{Engineering Overview and Yard Dilatation Scheme}

Since putting into production (nearly 40 years), Guizhou Aluminum Factory has discharged totally $10,000,000 \mathrm{~m}^{3}$ of the Bayer red mud and the sintering red mud. The no. 3 stock dump of the factory is mainly used for stacking the Bayer red mud produced from "wetting process". Due to its small particle size, poor permeability, and drainage difficulty, a lot of flow plastic or flexible plastic red mud with low strength deposits in the stock dump. At present, the pile-loading elevation of the stock dump is up to about $1,349 \mathrm{~m}$. There is only about $2,700,000 \mathrm{~m}^{3}$ of stock dump capacity at $1,355 \mathrm{~m}$ (closing stock dump elevation), which only meets the piling capacity for red mud to be discharged in the following 2 years (annual discharge amount of about 1,000,000 $\mathrm{m}^{3}$ ).

In general, the sintering red mud discharged from the "drying process" has better cementing and consolidation characteristics and can be used as the dam construction material. For example, the Taimagou red mud yard of Chalco Zhongzhou Branch uses the sintering red mud dam to stack Bayer red mud [17]. The practice proves that the red mud dam has good security and stability. In view of this, in order to utilize the existing red mud and red mud yard better and more efficiently, the dilatation scheme of no. 3 stock dump is designed as follows. (1) The sintering red mud shall be used as the subdam of red mud stockpile. In this case, the antileakage line can be increased from $1,355 \mathrm{~m}$ to $1,370 \mathrm{~m}$, that is, discharging the Bayer red mud by the internal wetting process can reach the elevation of $1,370 \mathrm{~m}$. (2) Change the pile loading by wetting process to the pile loading by drying process, with the tentative elevation of $1,390 \mathrm{~m}$. The pileloading gradient of Bayer red mud from drying process is $45^{\circ}$. The detailed pile-loading dilatation scheme is shown as Figure 1 .

\section{Physical and Mechanical Properties of Red Mud}

3.1. Test Scheme. To analyze the stability of red mud stockpile under rainfall condition, this paper firstly studies the physical, microscopic, and mechanical properties of three kinds of red mud (Bayer red mud from wetting process, Bayer red mud from drying process, and sintering red mud) by the laboratory test. The detailed test scheme is as follows.

3.1.1. Selection of Red Mud Materials. The sintering red mud has a certain structural form, so the sample is taken in the undistributed sampling method [18] directly. Moreover, the Bayer red mud from wetting process or drying process does not have the special structural form; thus, the sample is prepared directly in the remodeling method [19].

3.1.2. Physical Property. According to relevant provisions of Standard for Soil Test Method [20], three kinds of red mud are dried at $105^{\circ} \mathrm{C}$ and then sifted by $0.5 \mathrm{~mm}$. Then the specific gravity of red mud is tested in the pycnometer method, the liquid limit and plastic limit of red mud are tested by the photoelectric liquid-plastic limit combine tester, and the particle size gradation of red mud is tested by the laser particle size analyzer. Two parallel experiments were carried out for all the measurements. The difference between the two measurements should be in accordance with the provisions of the standard, and the average value of the two times was taken for analysis. 


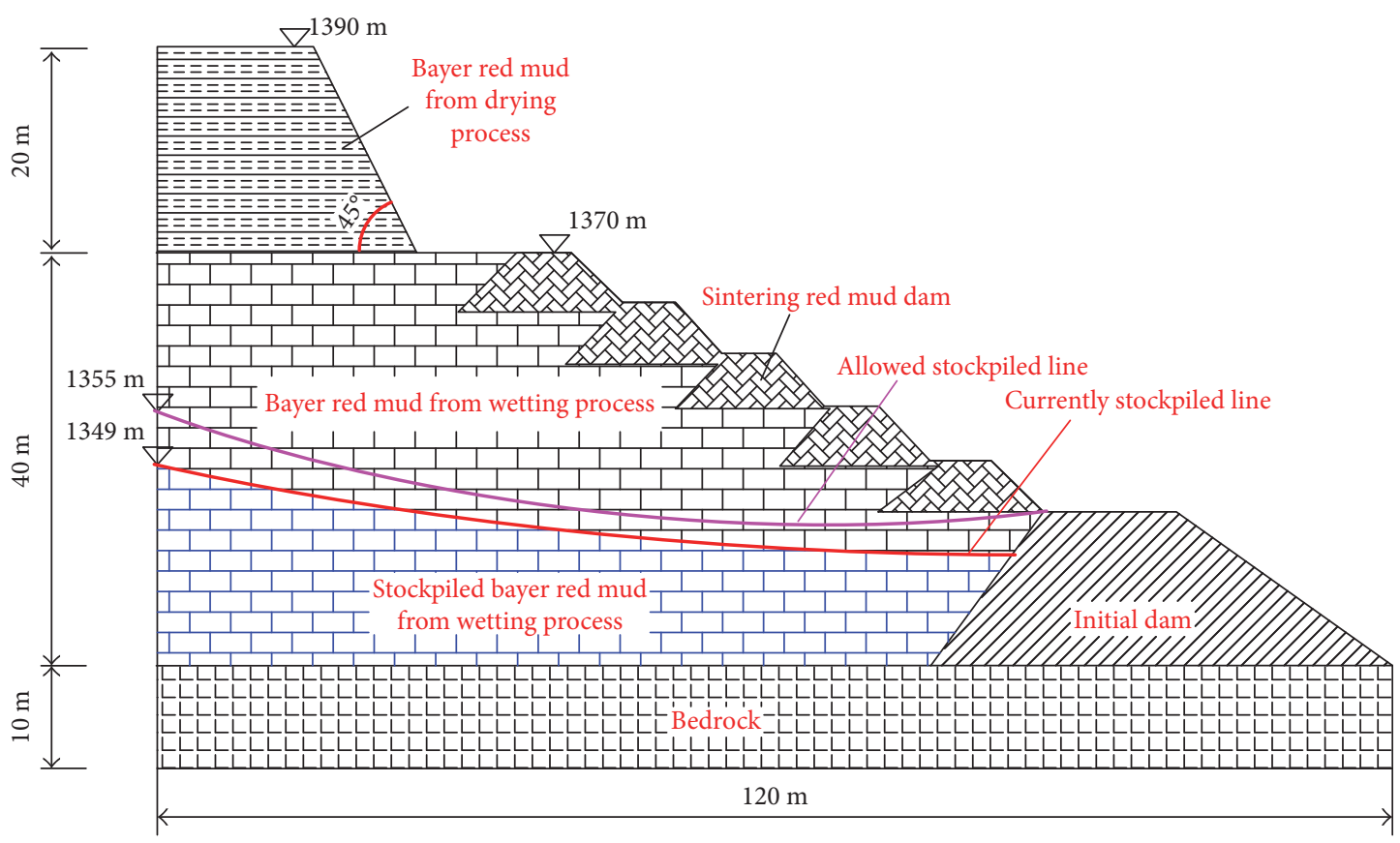

FiguRe 1: Design scheme of red mud stockpile dilatation.

3.1.3. Microscopic Property. According to relevant provisions of Method for Chemical Analysis of Clay [21], three kinds of red mud are dried at $105^{\circ} \mathrm{C}$ till the constant weight and sifted by 200 -mesh sieve after grinding. The chemical components and mineral compositions of red mud are analyzed and tested by X-ray fluorescence spectrometer (XRF) and X-ray diffractometer (XRD). The samples are broken into the relatively regular blocks of $1 \mathrm{~cm}^{3}$. After the process treatment of vacuum ion beam sputtering, metal spraying, and coating on the sample surface, the particle morphology of red mud after 2,000 times of magnification and the aggregation morphology among particles are observed by scanning electron microscope (SEM). Two parallel experiments were carried out, and the average value of the two times was taken for analysis.

3.1.4. Triaxial Shear Mechanical Property. Based on the actual piling status, in view of the drainage layer at the bottom of yard actually, the consolidation draining triaxial shear test (CD) is adopted. The test is conducted on the SJ1A.G strain controlled triaxial apparatus. The size of cylindrical specimens was $39.1 \mathrm{~mm}$ in diameter and $80 \mathrm{~mm}$ in height, which is in accordance with the tested sample size suggested by Standard for Soil Test Method [20]. All types of samples were tested under three confining pressures $\sigma_{3}$, that is, 100,200 , and $400 \mathrm{kPa}$. The confining pressure was first applied to the sample at a constant loading rate of $10 \mathrm{kPa} / \mathrm{s}$ until the desired level. Then, the axial stress $\sigma_{1}$ began to be imposed on the end surfaces of the rock sample at constant displacement rate of $0.015 \mathrm{~mm} / \mathrm{min}$ until failure took place. Three parallel experiments were carried out, and the average value of the two times was taken for analysis.

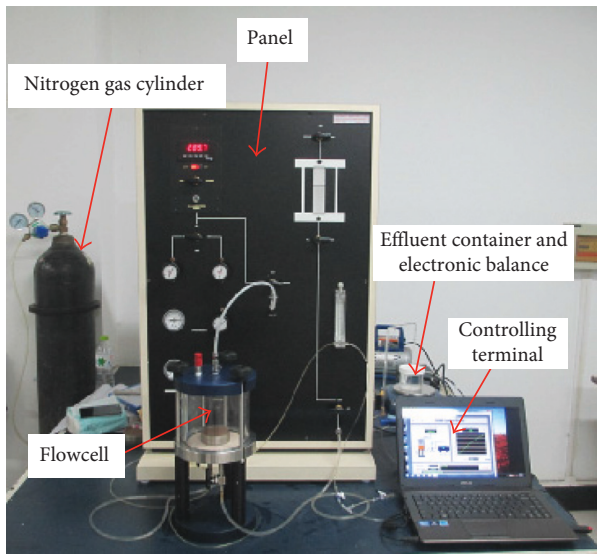

FIgURE 2: The unsaturated soil transient hydraulic characteristic cyclic test system.

3.1.5. Hydraulic Property. The hydraulic parameters of soil are important indexes to reflect the type of pore water action, which is a solid and considerable factor which could induce to the physical property change of soil. The parameters can be obtained by the soil-water characteristic function and transmissibility coefficient function. The experiment for getting the two functions is conducted on the unsaturated soil transient hydraulic characteristic cyclic test system (TRIM system) jointly researched and developed by unsaturated soil research group in Colorado School of Mines of America [19]. The full set of apparatuses are mainly composed of pressure control unit, soil sample room, computer control terminal (servo software), pore water collector and pipeline, water storage tank, and other components (Figure 2). The specific test process can refer to Feng et al. [19]. 
TABLE 1: Basic physical parameters of three kinds of red mud.

\begin{tabular}{|c|c|c|c|c|c|c|}
\hline Type of sample & Wet density & Specific gravity & Pore rate & Liquid limit (\%) & Plastic limit (\%) & Plasticity index \\
\hline Bayer red mud & $\sigma$ & 200 o & $2.72 \pm 0.02$ & $4889+006$ & $35.77 \pm 0.54$ & \\
\hline & & & & & & \\
\hline Sintering red mud & $1.58 \pm 0.01$ & $1.06 \pm 0.01$ & $2.85 \pm 0.02$ & $79.01 \pm 0.41$ & $59.47 \pm 0.22$ & $19.54 \pm 0.36$ \\
\hline
\end{tabular}

\subsection{Test Results}

3.2.1. Physical Property. The main physical property indexes of three kinds of red mud are shown in Table 1. It can be seen that compared to Bayer red mud, the sintering red mud has larger pore and relatively smaller specific gravity. Moreover, the liquid limit, plastic limit, and plasticity index of sintering red mud are significantly higher than those of Bayer red mud.

The particle size distribution curves of Bayer red mud and sintering red mud are shown in Figure 3. It can be seen that the particle size distribution uniformity of sintering red mud and Bayer red mud has larger differences. The clay particles with particle size of less than $5 \mu \mathrm{m}$ in sintering red mud are about $22 \%$ of total particles. The silt particles with particle size between $5 \mu \mathrm{m}$ and $75 \mu \mathrm{m}$ are $58 \%$ of total particles. The fine sand with particle size of more than $75 \mu \mathrm{m}$ is $20 \%$ of total particles. The calculation results show that the nonuniform coefficient of sintering red mud is $C_{\mathrm{u}}=12$ and the coefficient of curvature is $C_{\mathrm{c}}=4.08$, which cannot meet $C_{\mathrm{u}}>5$ and $C_{\mathrm{c}}=1 \sim 3$ at the same time. Thus, the sintering red mud is the poorly graded soil. Similarly, the clay particles with particle size of less than $5.0 \mu \mathrm{m}$ in the particle composition of Bayer red mud are about $50 \%$ of total particles, and the particle size of Bayer red mud is smaller and less than $80 \mu \mathrm{m}$ with comparatively uniform particle size distribution. After calculation, the nonuniform coefficient of Bayer red mud is $C_{\mathrm{u}}=9$, and the coefficient of curvature is $C_{\mathrm{c}}=0.83$, which cannot meet $C_{\mathrm{u}}>5$ and $C_{\mathrm{c}}=1 \sim 3$ at the same time. Thus, the Bayer red mud is also the poorly graded soil.

3.2.2. Microscopic Property. The chemical components, mineral compositions, and microstructure forms of three kinds of red mud are shown in Table 2, Figures 4 and 5, respectively.

From Table 2, the chemical component types of three kinds of red mud are basically the same, but the component contents of sintering red mud and Bayer red mud have larger differences. The contents of $\mathrm{CaO}$ in sintering red mud are significantly higher than those in Bayer red mud, but the contents of oxides such as $\mathrm{Al}_{2} \mathrm{O}_{3}, \mathrm{Na}_{2} \mathrm{O}$, and $\mathrm{K}_{2} \mathrm{O}$ are significantly lower than those in Bayer red mud. The contents of oxides in chemical components of two kinds of Bayer red mud have little difference.

From Figure 4, the mineral compositions of sintering red mud and Bayer red mud are different due to difference of ore composition and treatment process. The main mineral compositions of Bayer red mud are cancrinite, hydrogrossular, calcite, and xonotlite. (Figure 4(a)). The mineral compositions of sintering red mud mainly include calcite, dicalcium silicate, tricalcium silicate, tricalcium aluminate, and hydrogrossular. (Figure 4(b)).

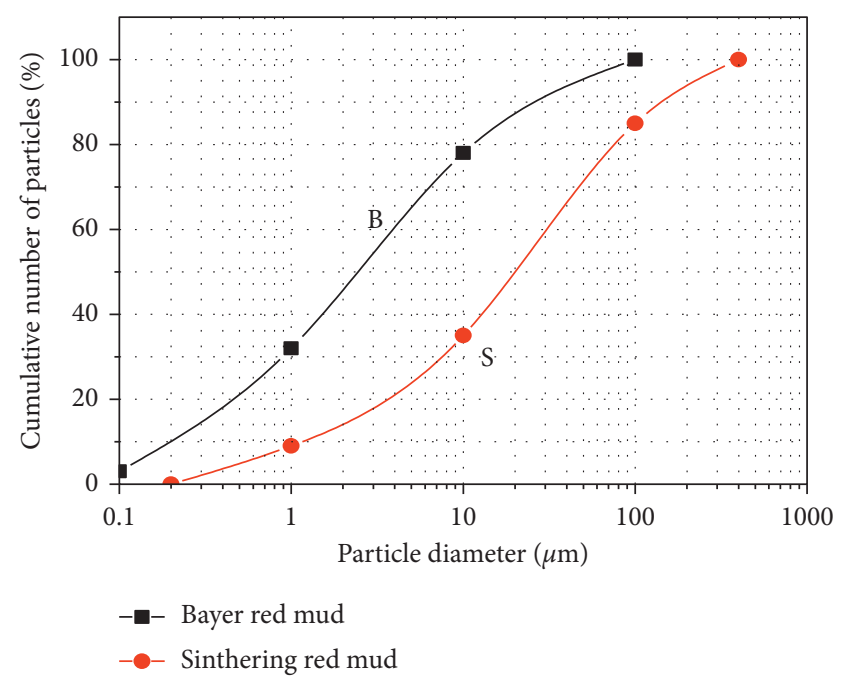

FIgure 3: Particle size distribution curve of two kinds of red mud.

The results in Figures 5(a) and 5(b) indicate that Bayer red mud from wetting process and Bayer red mud drying process are composed of fine particles and show the loose distribution between particles without forming large clustering blocks. The particles aggregation of Bayer red mud from drying process is larger than that of Bayer red mud from wetting process, with a larger compaction rate. From Figure 5(c), the sintering red mud is composed of largeparticle cementing blocks, with dense aggregation of particles, significant clustering performance, and larger crack between blocks. It is the porous aerial structure.

3.2.3. Triaxial Shear Mechanical Property. The stress-strain curves of three kinds of red mud are shown in Figure 6.

From Figure 6(a), the stress-strain curves of Bayer red mud from wetting process are strain hardening type, and the stress and strain shows an approximate linear relation. With increase of confining pressure, the slope of curve is increased gradually. During the test, the sample is compressed to the extreme, and the red mud manifests the plastic failure. The result of Figure 6(b) indicates that the stress-strain curves of Bayer red mud from drying process behave weak hardening and tend to be stable after reaching the peak at the axial strain of about $4 \%$. Moreover, with increase of confining pressure $\sigma_{3}$, the peak point is larger. It also manifests the form of plastic failure. The result of Figure 6(c) indicates that the stress-strain curves of sintering red mud behave as strain softening, and the stress difference $\left(\sigma_{1}-\sigma_{3}\right)$ shows the trend of firstly increasing to the peak point, then declining rapidly, and finally tending to be stable as the axial strain increases. After the stress difference $\left(\sigma_{1}-\sigma_{3}\right)$ reaches peak at the axial strain of 
Table 2: Chemical composition of the three kinds of red mud (w/\%).

\begin{tabular}{|c|c|c|c|c|c|c|c|c|c|}
\hline Type & $\mathrm{l}_{2} \mathrm{O}_{3}$ & $\mathrm{SiO}_{2}$ & $O_{3}$ & $\mathrm{O}$ & 0 & $\mathrm{~K}_{2}$ & $\mathrm{O}$ & $\mathrm{TiO}_{2}$ & $\mathrm{SO}_{3}$ \\
\hline & $0.80=$ & $2.35 \pm$ & $73 \pm 0.06$ & & $8.83 \pm 0.07$ & & & $4.98 \pm 0.05$ & $3.00 \pm 0.02$ \\
\hline from & $0.52+$ & $22.47 \pm 0.16$ & & & & & & & 201 \\
\hline Sintering red mud & $7.28 \pm 0.07$ & $24.02 \pm 0.18$ & $8.50 \pm 0.05$ & $44.00 \pm 0.20$ & $0.69 \pm 0.05$ & $0.25 \pm 0.03$ & $1.37 \pm 0.05$ & $4.17 \pm 0.08$ & $1.09 \pm 0.02$ \\
\hline
\end{tabular}

about $1 \%$, the sample has the sudden failure and generates the shearing crack of the entire sample. The bearing capacity is reduced rapidly, manifesting the form of brittle failure.

The peak strengths of red mud under different confining pressure are shown as Table 3. It is observed that, the strengths of three kinds of red mud under the same confining pressure are sintering red mud, Bayer red mud from drying process, and Bayer red mud from wetting process successively from high to low. The strengths of sintering red mud are much higher than those of the other two kinds of red mud. The strength of sintering red mud is about 4.2 times of that of Bayer red mud from wetting process on average, and the strength of Bayer red mud from drying process is about 1.5 times of that of Bayer red mud from wetting process on average. According to Mohr-Coulomb criterion, the shear strength parameters of three kinds of red mud are shown in Table 3. It shows that, the internal friction angle $\varphi$ values of three kinds of red mud have small difference and the value of Bayer red mud from drying process is slightly higher than other two kinds of red mud. The cohesion force $c$ of sintering red mud is much larger than that of Bayer red mud, and the value is $356.42 \mathrm{kPa}$, with relatively high shear strength. The main reason is that the sintering red mud is rich in cementing minerals and generates higher cementing strength after cementing and hardening during the stacking. Therefore, the sintering red mud can be used as the subdam to reduce the risks of stockpile collapse and dam break. The cohesion force $c$ of Bayer red mud from drying process is 1.5 times of that of the Bayer red mud from wetting process, indicating that the shear strength of Bayer red mud is directly related to the factors such as water content and compaction degree. The smaller the water content is, the larger the compaction degree is and the larger the shear strength of Bayer red mud is.

For the deformation characteristic, the elasticity modulus $E$ of sintering red mud is significantly less than that of Bayer red mud, and the elasticity modulus of Bayer red mud from wetting process is slightly more than that of Bayer red mud from drying process. Poisson ratio $\mu$ values of three kinds of red mud have small difference.

3.2.4. Hydraulic Property. Based on the relation curve between volumetric water content and time in the course of moisture desorption and moisture absorption of sintering red mud and Bayer red mud, the test data are fitted by the program HYDRUS-1D. If the relation curve between volumetric water content and time by fitting is consistent with the test curve (as shown in Figure 7), the hydraulic characteristic parameter values of the sample by the computer program fitting are actual hydraulic characteristic parameter values of the sample. The hydraulic characteristic parameter values of sintering red mud and Bayer red mud are shown in Table 4, and the corresponding characteristic curves are shown in Figure 8. In Table 4, $\alpha$ is the reciprocal of air-entry pressure $\varphi_{\mathrm{a}}$, which is defined as the pressure value when the gas enters the largest pore in the soil. $\theta_{\mathrm{r}}$ is the remaining moisture content, and when the volume of water content is lower than $\theta_{\mathrm{r}}$, the increase of the matrix suction does not cause a significant change in the volumetric water content. $\theta_{\mathrm{s}}$ is the saturated volumetric water content, which is the ratio of the volume of water in the soil to the total volume of the soil under the saturated condition. The soil pore size distribution function $n$ determines the form of pore water. $k$ is the permeability coefficient function and $k_{\text {sat }}$ is the saturated permeability coefficient value. $\alpha$ and $n$ are empirical parameters, which can be obtained directly or by fitting in the characteristic curve during the test. The superscript $d$ in the functional symbol refers to the course of draining and moisture desorption, while $\mathrm{w}$ refers to the course of soaking and moisture absorption.

When two kinds of red mud are in the courses of moisture desorption and moisture absorption, the landwater characteristic curves only coincide nearby the residual water content. In the case of the same water contents, the matric suctions of two kinds of red mud samples in reaching the water content in the course of moisture desorption are greater than the matric suctions in the course of moisture absorption, and such difference shows decreasing trend as water content reduces. The difference is called as "hysteresis effect" of unsaturated soil. The hysteresis effect of land-water characteristic curves of Bayer red mud is significantly larger than that of sintering red mud. The path of moisture getting in and out of the red mud is different at different stages of hydraulic course, so the saturated water content values of red mud have large differences influenced by the courses of moisture absorption and moisture desorption. Between these two kinds of red mud, Bayer red mud has the largest difference in the saturated water content as 0.24 , and the sintering red mud is only 0.11 . However, the saturated water content values of these two kinds of red mud at moisture desorption stage are always larger than those at the moisture absorption stage. In other words, under the effect of cyclic hydraulic conditions, the saturated water content values of red mud by free water absorption are smaller than the initial saturation values (before the test, the saturation value of the artificial saturated sample is equal to the pore rate of the sample in numerical value). In addition, regardless of any types of red mud or the environment of 


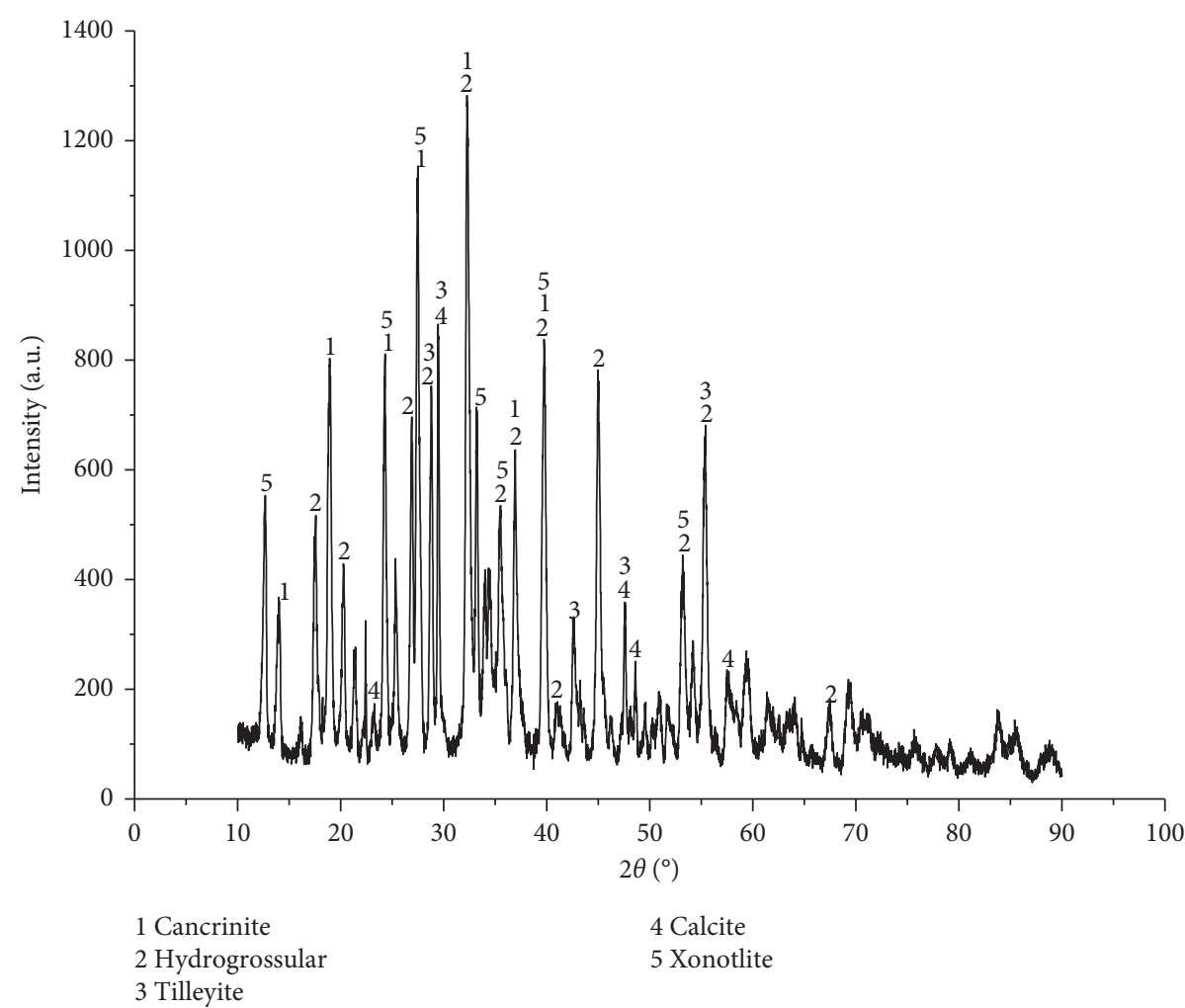

(a)
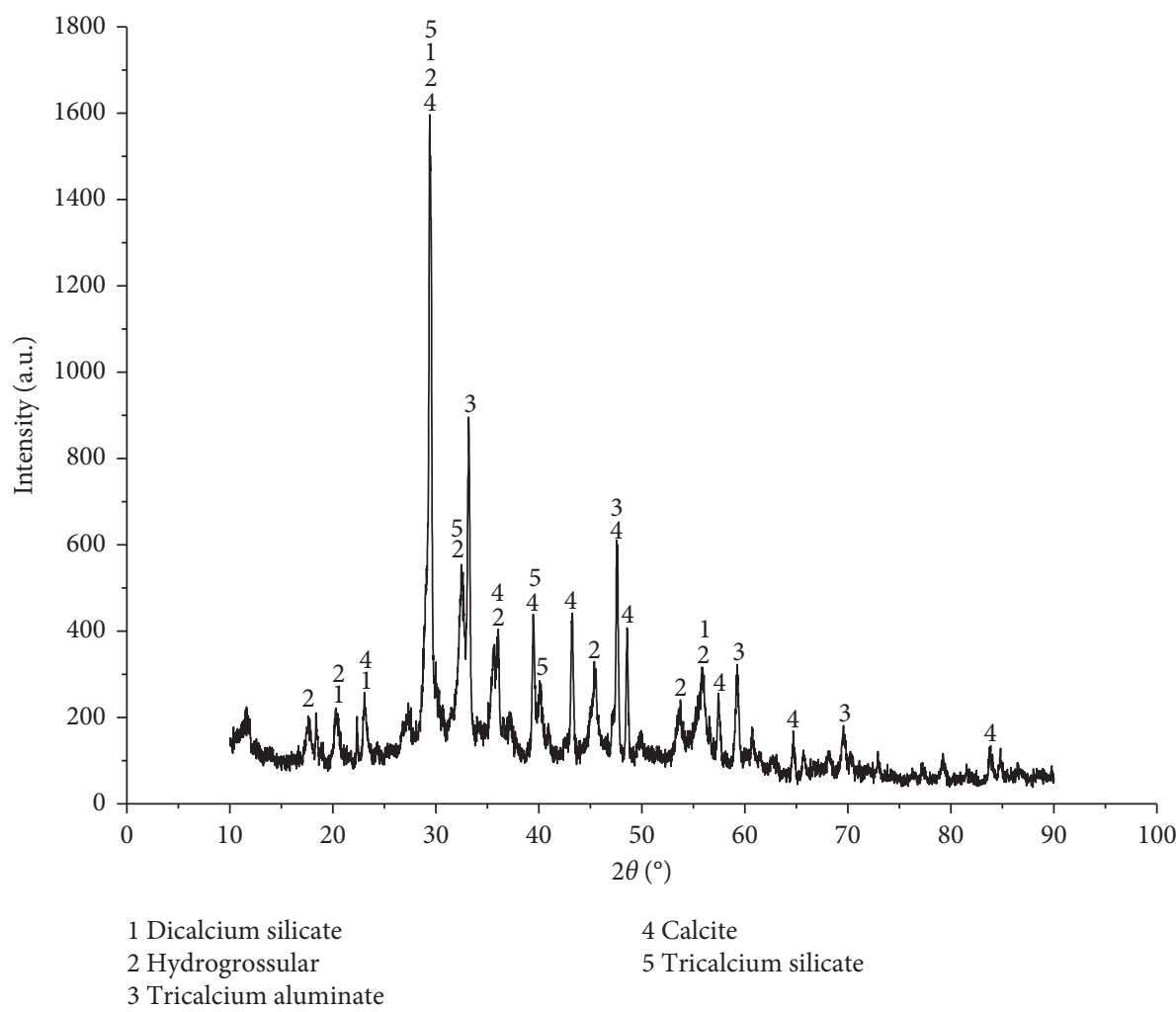

4 Calcite

5 Tricalcium silicate

(b)

FIGURE 4: XRD pattern of different red mud: (a) Bayer red mud and (b) sintering red mud. 


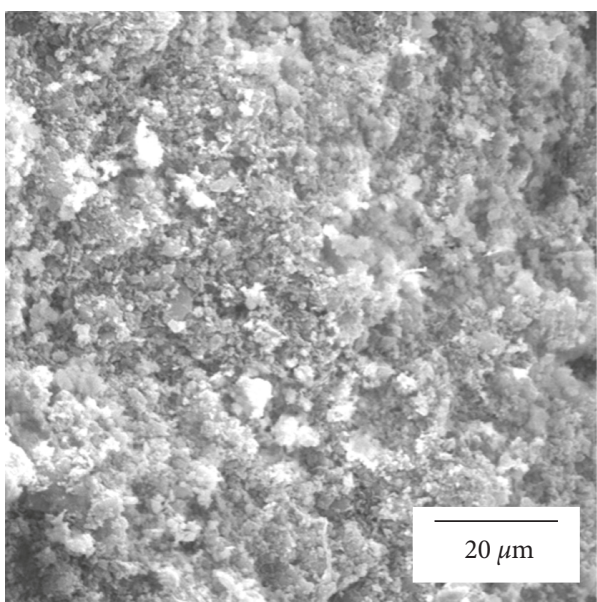

(a)

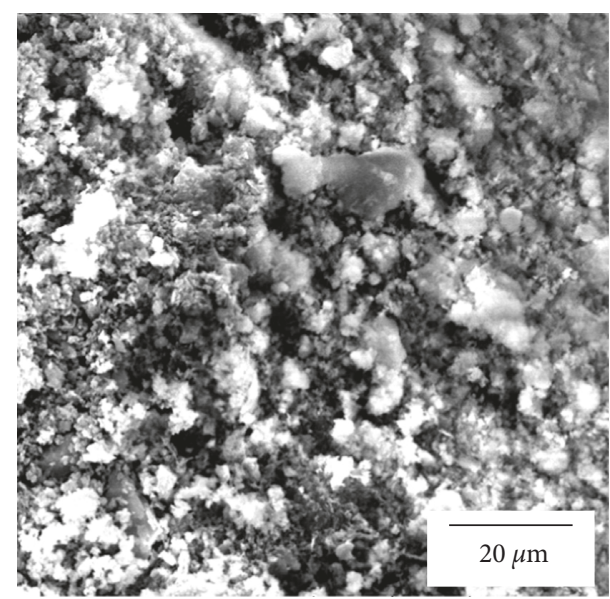

(b)

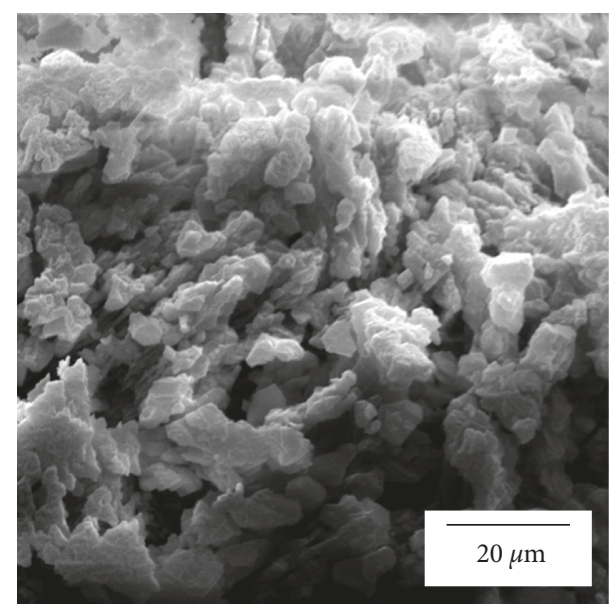

(c)

FIGURE 5: SEM diagram of three kinds of red mud: (a) Bayer red mud from wetting process, (b) Bayer red mud from drying process, and (c) sintering red mud.

hydraulic course, the suctions in the red mud samples are changed most rapidly near the residual water content and inlet pressure value water content.

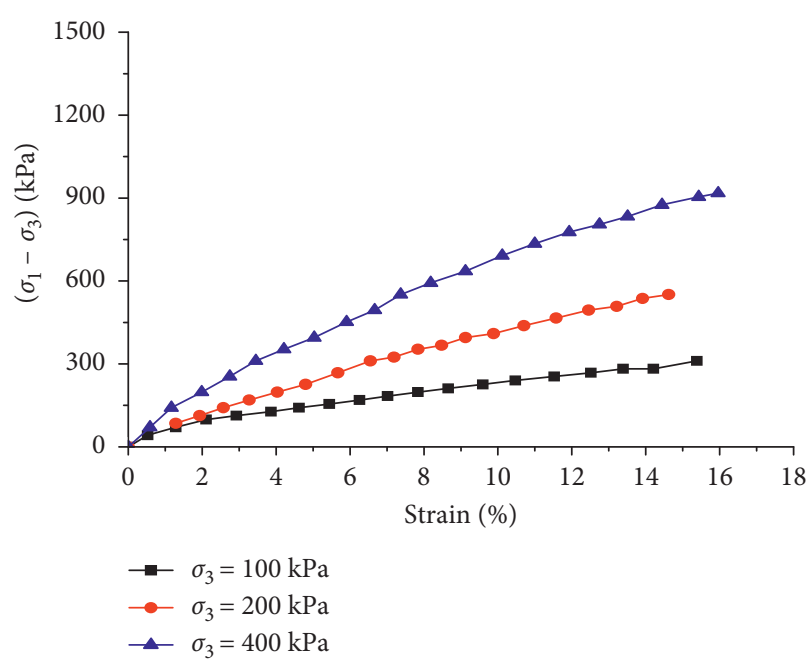

(a)

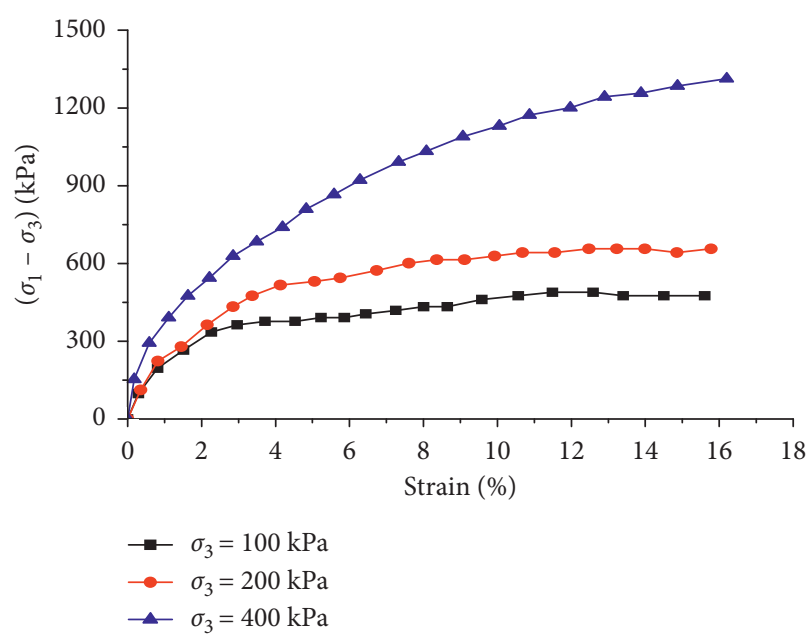

(b)

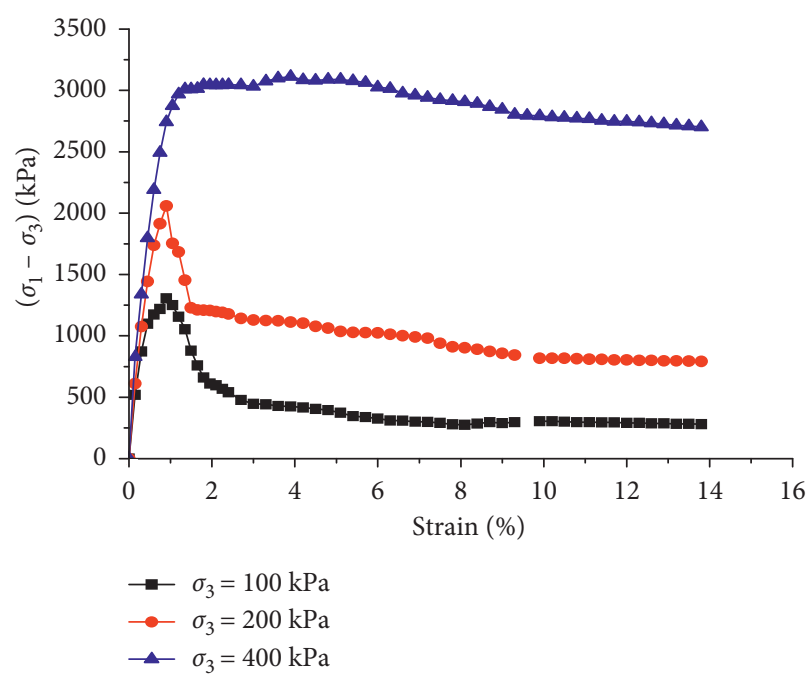

(c)

Figure 6: Triaxial stress-strain curves of the tested samples: (a) Bayer red mud from wetting process, (b) Bayer red mud from drying process, and (c) sintering red mud. 
TABLE 3: Strength and deformation indicators of the three kinds of red mud.

\begin{tabular}{|c|c|c|c|c|c|c|c|}
\hline \multirow{2}{*}{ Type of sample } & \multicolumn{3}{|c|}{ Peak strength } & \multirow{2}{*}{$\begin{array}{l}\text { Cohesion } \\
c(\mathrm{kPa})\end{array}$} & \multirow{2}{*}{$\begin{array}{c}\text { Internal friction } \\
\text { angle } \varphi\left({ }^{\circ}\right)\end{array}$} & \multirow{2}{*}{$\begin{array}{c}\text { Elasticity modulus } \\
E(\mathrm{MPa})\end{array}$} & \multirow{2}{*}{ Poisson ration $\mu$} \\
\hline & $\sigma_{3}=100 \mathrm{kPa}$ & $\sigma_{3}=200 \mathrm{kPa}$ & $\sigma_{3}=400 \mathrm{kPa}$ & & & & \\
\hline $\begin{array}{l}\text { Bayer red mud from } \\
\text { wetting process }\end{array}$ & 280.16 & 485.12 & 870.46 & 38.49 & 34.12 & 30.16 & 0.365 \\
\hline $\begin{array}{l}\text { Bayer red mud from } \\
\text { drying process }\end{array}$ & 489.25 & 620.16 & $1,308.61$ & 58.01 & 35.80 & 28.51 & 0.334 \\
\hline Sintering red mud & $1,301.21$ & $2,057.10$ & $3,110.78$ & 356.42 & 33.58 & 15.78 & 0.345 \\
\hline
\end{tabular}

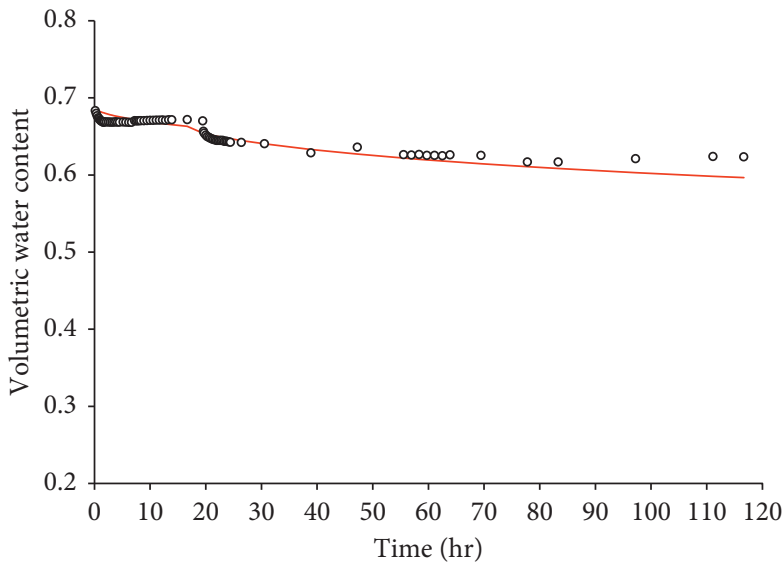

- Experimental

- Model

(a)

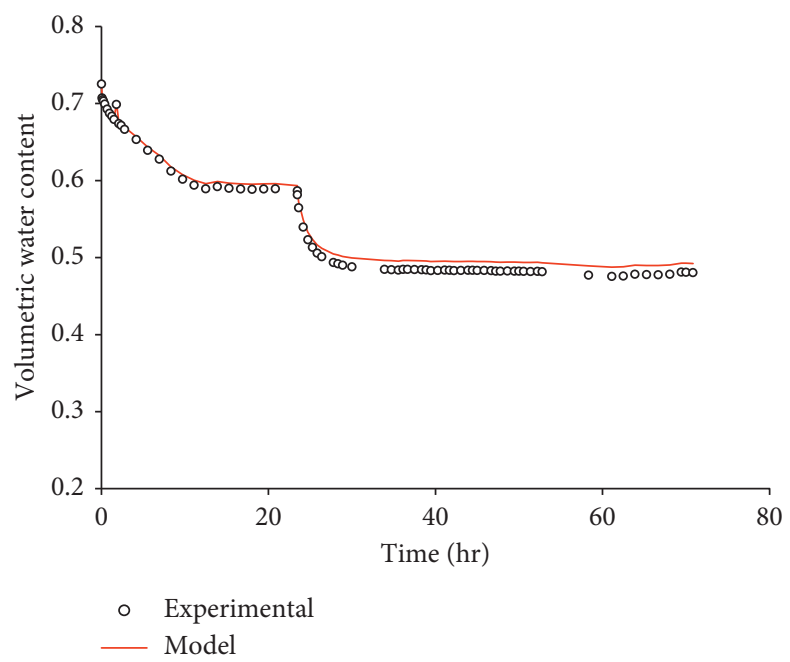

(c)

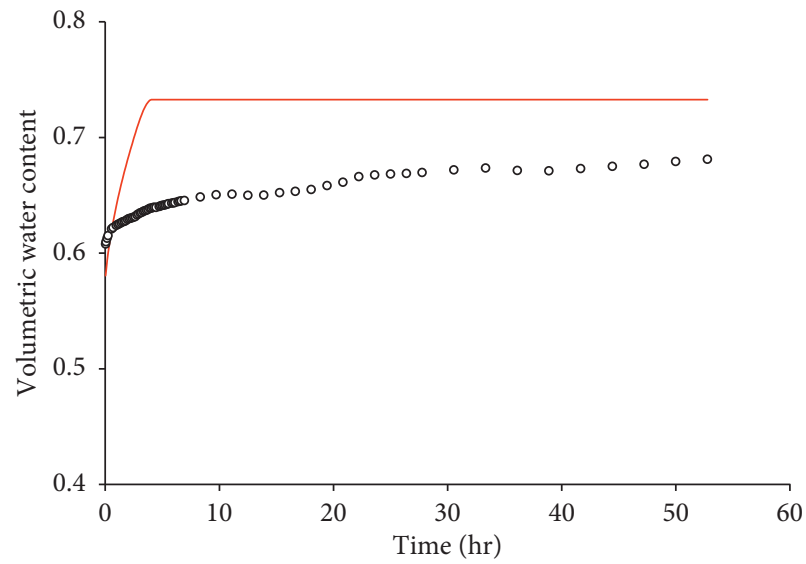

- Experimental

- Model

(b)

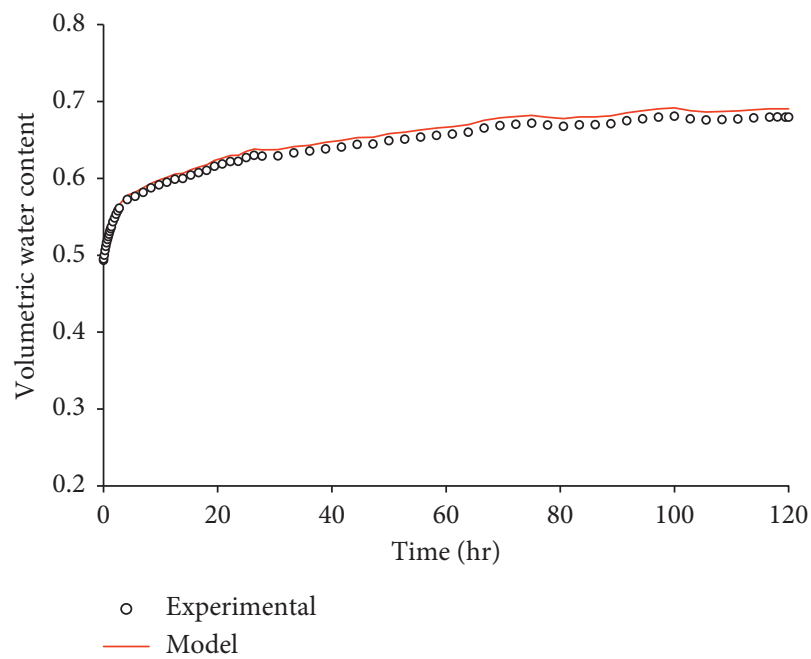

(d)

FIGURE 7: Comparison of fitting value and actual value of relation curve between red mud volumetric water content and time under moisture desorption-moisture absorption hydraulic path conditions. (a) Moisture desorption test stage of sintering red mud. (b) Moisture absorption test stage of sintering red mud. (c) Moisture desorption test stage of Bayer red mud. (d) Moisture absorption test stage of Bayer red mud.

Similarly, the permeability coefficient characteristic curves of two kinds of red mud also reveal the significant hysteresis effect. Moreover, the hysteresis effect of permeability coefficient characteristic curve of Bayer red mud is significantly higher than that of sintering red mud. When the same type of sample has the same water content, the permeability coefficient in the course of moisture absorption is greater than that in the course of moisture desorption. However, in the case of reaching the saturation under different hydraulic conditions, the saturated permeability coefficient value in the course of moisture absorption is always smaller than that in the course of moisture desorption.

The main reasons for the hysteresis effect of Bayer red mud significantly larger than that of sintering red mud are as follows: (1) The sintering red mud contains vast cement hydraulic cementing minerals and calcites, and the 
TABle 4: Hydraulic characteristic parameters of red mud.

\begin{tabular}{lcccccccccc}
\hline Type of sample & $\alpha^{\mathrm{d}}\left(\mathrm{kPa}^{-1}\right)$ & $\alpha^{\mathrm{w}}\left(\mathrm{kPa}^{-1}\right)$ & $n^{\mathrm{d}}$ & $n^{\mathrm{w}}$ & $\theta_{\mathrm{s}}{ }^{\mathrm{d}}$ & $\theta_{\mathrm{s}}{ }^{\mathrm{w}}$ & $\theta_{\mathrm{r}}{ }^{\mathrm{d}}$ & $\theta_{\mathrm{r}}{ }^{\mathrm{w}}$ & $k_{\text {sat }}{ }^{\mathrm{d}}(\mathrm{cm} / \mathrm{s})$ & $k_{\text {sat }}{ }^{\mathrm{w}}(\mathrm{cm} / \mathrm{s})$ \\
\hline Bayer red mud & 0.012 & 0.015 & 1.70 & 1.80 & 0.69 & 0.45 & 0.11 & 0.11 & $5.0 E-06$ & $4.0 E-06$ \\
Sintering red mud & 0.012 & 0.015 & 2.10 & 2.20 & 0.73 & 0.62 & 0.26 & 0.26 & $1.0 E-05$ & $8.0 E-06$ \\
\hline
\end{tabular}

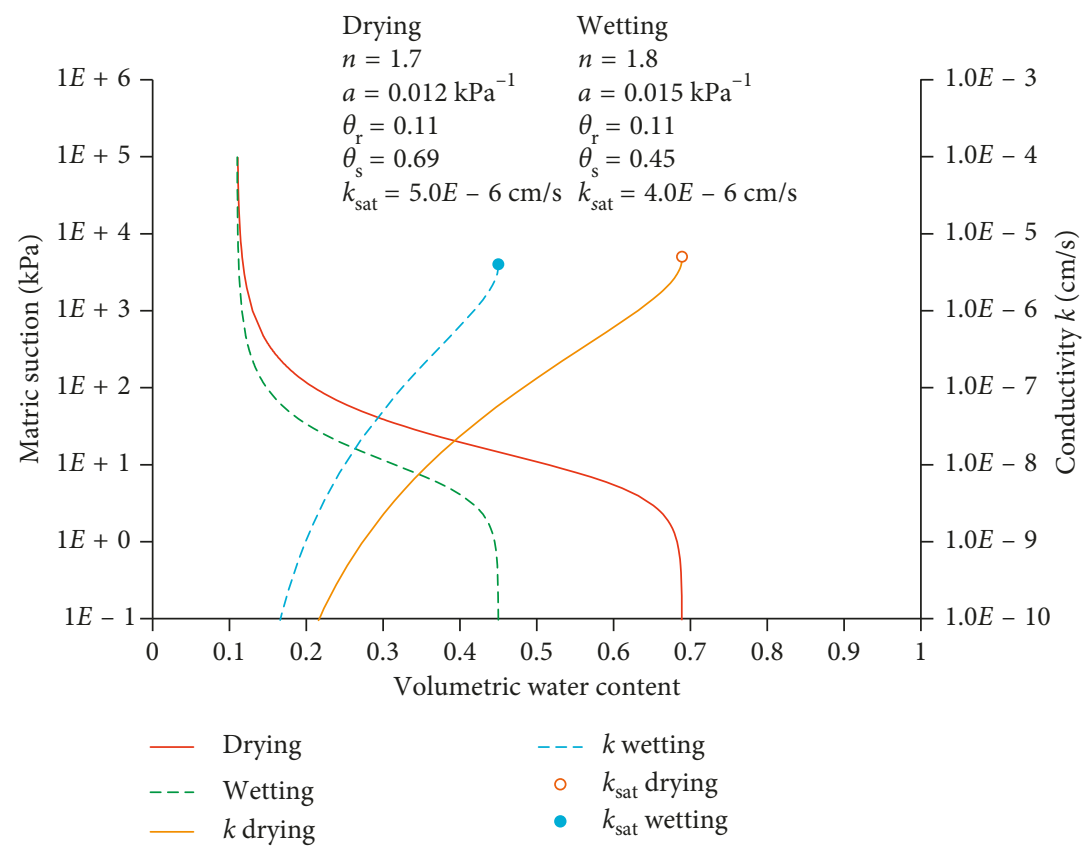

(a)

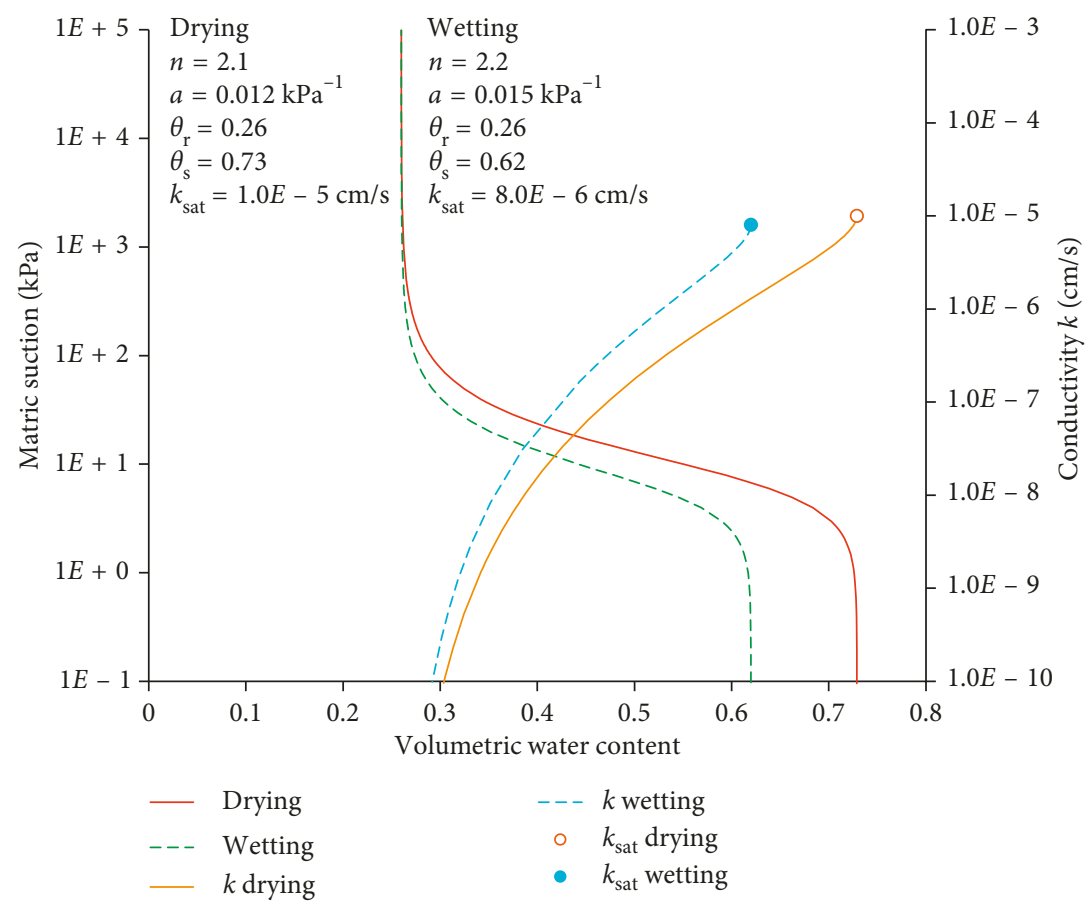

(b)

FIGURE 8: Hydraulic characteristic curves of red mud under moisture desorption-moisture absorption hydraulic path conditions: (a) Bayer red mud and (b) sintering red mud. 


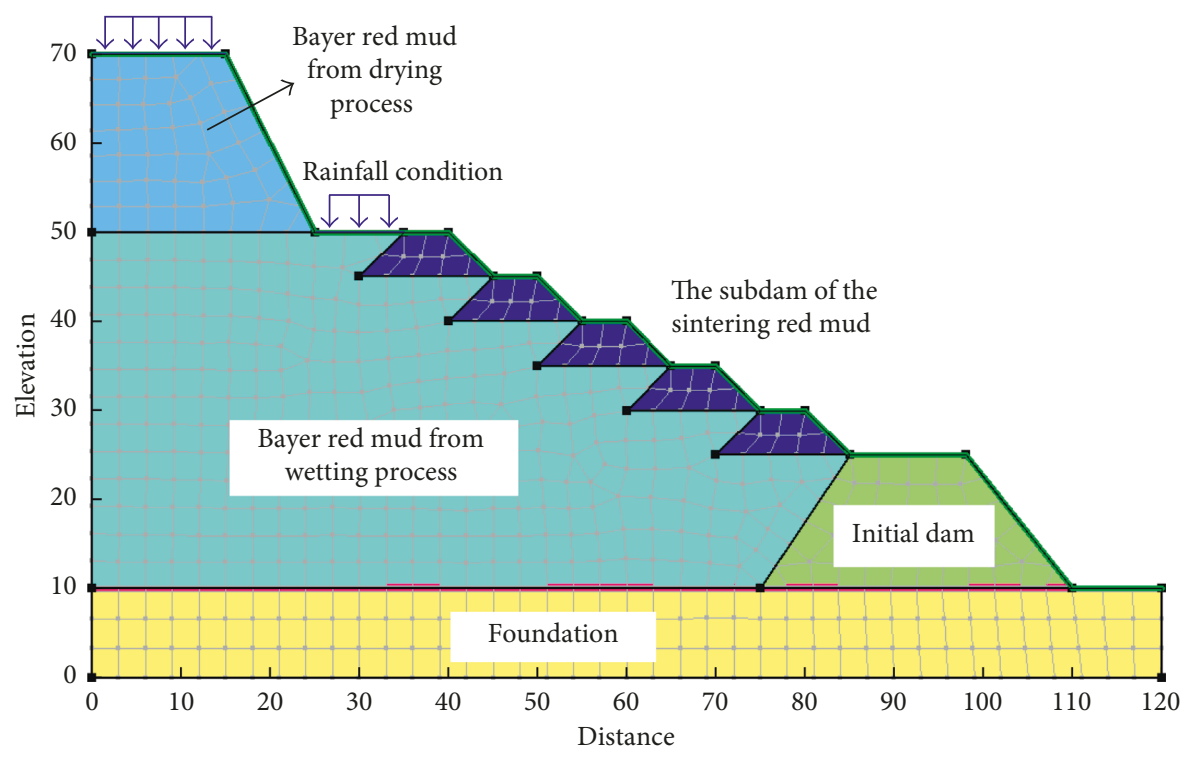

FIgUre 9: Calculation model.

cementation enables the particles to cement together and form the macroporous aerial structure. Bayer red mud has fine particles and larger specific surface area, so the particles have greater absorption effect (Figures 4 and 5). The clayey soil with large specific surface area and smaller pore size has more significant hysteresis phenomenon [22]. (2) The Bayer red mud contains more soluble alkaline oxides (such as $\mathrm{Na}_{2} \mathrm{O}$ and $\mathrm{K}_{2} \mathrm{O}$ ), while the sintering red mud and mixed red mud contain more insoluble calcium and magnesium carbonates (Table 2). The soluble salt between Bayer red mud particles constitutes the cementation between particles under the low water content, but is softening or is destroyed under the new humidification environment, with the sensitive reaction to water. In view of the above reasons, the land-water characteristic curves of Bayer red mud in two different hydraulic paths of moisture desorption and moisture absorption have larger differences, while the water infiltration paths of sintering red mud under two different hydraulic paths are basically the same with smaller difference in the land-water characteristic curves. It indicates that the water sensitivity of Bayer red mud is larger than that of sintering red mud, and also the red mud stockpile stability of Bayer red mud in the case of the dry-wet cycle of drying and rainfall is influenced more greatly than that of sintering red mud under the same rainfall condition. In addition, the permeability coefficient of Bayer red mud in the hydraulic path of moisture desorption is smaller than that of sintering red mud. The red mud leachate inside the stockpile is not easily discharged, resulting in excessively high water content of red mud at bottom of stockpile and the greater influence on stockpile stability.

\section{Stockpile Stability Calculation of Red Mud in Mixing Stack}

4.1. Calculation Model and Boundary Conditions. The numerical analyses were performed using the Geo-Studio software. According to the design scheme in Chapter 2,
TABLE 5: Three rainfall conditions selected by model calculation.

\begin{tabular}{lcc}
\hline $\begin{array}{l}\text { Rainfall } \\
\text { conditions }\end{array}$ & Rainfall & $\begin{array}{c}\text { Rainfall } \\
\text { types }\end{array}$ \\
\hline I & $5 \mathrm{~d} \times 133.20 \mathrm{~mm} / \mathrm{d}=666.00 \mathrm{~mm}$ & $\begin{array}{c}\text { Equal } \\
\text { strength }\end{array}$ \\
II & $\begin{array}{c}2 \mathrm{~d} \times 133.20 \mathrm{~mm} / \mathrm{d} \\
+1 \mathrm{~d} \times 155.80 \mathrm{~mm} / \mathrm{d}\end{array}$ & Single peak \\
& $+2 \mathrm{~d} \times 133.20 \mathrm{~mm} / \mathrm{d}=688.60 \mathrm{~mm}$ & $\begin{array}{c}\text { Equal } \\
\text { strength }\end{array}$ \\
III & $10 \mathrm{~d} \times 47.97 \mathrm{~mm} / \mathrm{d}=479.70 \mathrm{~mm}$ & \\
\hline
\end{tabular}

the calculation model is established as shown in Figure 9. The on-site survey and investigation reveal that the bottom of red mud reservoir is the hard and dense limestone, so it can be treated directly as the foundation without considering the influence. The upper part of the foundation is paved with impermeable layer and is treated as the impervious layer while calculating. The upper part of impermeable layer is paved with drainage layer, in favor of the leachate discharge deposited at the bottom of the red mud stock dump; hence, the initial condition of ground water flow and the effect of rainfall intensity to increase the ground water are ignored in the calculation. Considering that the impervious layer was established above the sintering red mud dam to protect the slope stability, the rainfall intensity infiltrate to sintering red mud dam was also ignored.

As for boundary conditions, the left side of the model was constrained horizontally, whereas the right side and the bottom of the model were fixed horizontally and vertically.

The analysis is conducted by three modules of SEEP/W (underground water seepage analysis software), SIGMA/W (stress deformation finite element analysis software), and SLOPE/W (slope stability analysis software) of Geo-Studio software. The specific steps are as follows: (1) The change rule of red mud stockpile seepage field under rainfall infiltration conditions is calculated by SEEP/W module, and the rainfall 
TABLE 6: The related parameters used in the three modules of SEEP/W, SIGMA/W, and SLOPE/W.

\begin{tabular}{|c|c|c|c|c|c|c|c|c|c|c|c|}
\hline \multirow{2}{*}{ Name } & \multicolumn{5}{|c|}{ SEEP/W module } & \multicolumn{3}{|c|}{ SIGMA/W module } & \multicolumn{3}{|c|}{ SLOPE/W module } \\
\hline & $\alpha\left(\mathrm{kPa}^{-1}\right)$ & $n$ & $\theta_{\mathrm{s}}$ & $\theta_{\mathrm{r}}$ & $k_{\text {sat }}(\mathrm{cm} / \mathrm{s})$ & $E(\mathrm{MPa})$ & $\mu$ & $\gamma\left(\mathrm{kN} \cdot \mathrm{m}^{-3}\right)$ & $c(\mathrm{kPa})$ & $\varphi\left(^{\circ}\right)$ & $\gamma\left(\mathrm{kN} \cdot \mathrm{m}^{-3}\right)$ \\
\hline $\begin{array}{l}\text { Bayer red mud from } \\
\text { drying process }\end{array}$ & 0.015 & 1.80 & 0.45 & 0.11 & $4.0 E-06$ & 28.51 & 0.334 & 18.5 & 58.01 & 35.80 & 18.5 \\
\hline $\begin{array}{l}\text { Bayer red mud from } \\
\text { wetting process }\end{array}$ & - & - & - & - & $4.0 E-06$ & 30.16 & 0.365 & 17.5 & 38.49 & 34.12 & 17.5 \\
\hline Sintering red mud & 0.015 & 2.20 & 0.62 & 0.26 & $8.0 E-06$ & 15.78 & 0.345 & 15.8 & 356.42 & 33.58 & 15.8 \\
\hline Initial dam & - & - & - & - & $8.0 E-07$ & 32.10 & 0.321 & 20.5 & 630.10 & 35.50 & 20.5 \\
\hline
\end{tabular}

condition as the boundary condition is set in the program by the definite function. (2) The pore water pressure data of seepage field in various nodes of red mud stockpile under different rainfall conditions calculated by SEEP/W module are imported in the SIGMA/W module for stress and deformation calculation. (3) The stress and deformation data obtained are imported to SLOPE/W module, and the stability coefficient of red mud stockpile under different rainfall conditions is calculated.

4.2. Material Parameters. In Baiyun District for the red mud stockpiles, the maximum average annual rainfall had been 1,258.6 mm between 1999 and 2009, with the maximum rainfall of $133.20 \mathrm{~mm}$ on a single day, maximum continuous rainfall of $479.70 \mathrm{~mm}$, and maximum rainfall of $155.80 \mathrm{~mm}$ during the 50-year return period. Accordingly, this paper selects three rainfall conditions, and the details are shown in Table 5. Condition I represents the possible maximum intensity of rainfall of the red mud stockpile. In this condition, the rainfall intensity is $133.20 \mathrm{~mm} / \mathrm{d}$, and the rainfall duration is $5 \mathrm{~d}$. Condition II represents the worst rainfall condition of the red mud stockpile during the 50 -year return period. In this condition, the rainfall intensity is $133.20 \mathrm{~mm} / \mathrm{d}$ in the first two and the last two days, the rainfall intensity is $155.80 \mathrm{~mm} / \mathrm{d}$ in the third day. Condition III represents the possible rainfall with the longest duration for the red mud stockpile. The rainfall intensity is $47.97 \mathrm{~mm} / \mathrm{d}$, and the rainfall duration is $10 \mathrm{~d}$ in this condition.

While calculating the seepage field of red mud stockpile under the rainfall conditions by SEEP/W module, the rainfall conditions should be set in the software in the form of boundary and are imported to SEEP/W module by the functional relation between boundary flux and time in accordance with the rainfall intensity and number of raining days selected. In this module, the hydraulic characteristic parameters of sintering red mud and Bayer red mud from the wetting process were used. In SIGMA/W module, the sintering red mud and Bayer red mud were modeled by using a linear elastic relationship. In SLOPE/W module, the sintering red mud and Bayer red mud were simulated by using an elastoplastic relationship based on the Mohr-Coulomb criterion. The related parameters used in the three modules of SEEP/W, SIGMA/W, and SLOPE/W are summarized in Table 6.

4.3. Seepage Field and Stress Field. The change rule of red mud stockpile seepage field under three rainfall infiltration conditions is shown in Figure 10. The pore water pressure contour in the surface layer of stockpile is dense, while it has no significant change at the bottom of stockpile. With the increase of rainfall intensity and duration, the fluctuation of pore water pressure line in the surface of the stockpile become greater. During the rainfall infiltration process of stockpile, the surface layer of stockpile forms a transient saturation zone. The pore water pressure in the surface layer of stockpile is ever-increasing and rises to the zero or positive pore water pressure from the initial negative pore water pressure gradually.

The vertical and effective stress distribution graph of red mud stockpile under three rainfall conditions is shown as Figure 11. It can be seen that the stress contour in the surface layer of stockpile is dense, and especially it is the densest in the lower part of surface layer, and the stress concentration zone is generated in the surface layer. From the wetting front position by analysis in combination with the change curve of pore water pressure, the stress concentration zone is generated near the depth of wetting front, demonstrating that the stockpile is easily subject to the superficial layer failure along the wetting front.

4.4. Stability Coefficient Calculation Result. The stability coefficient calculation results of potential slip face and side slope under three rainfall conditions are shown in Figure 12.

From Figure 12, the stability coefficients of two kinds of red mud stockpiles in mixing pile under three rainfall conditions are respectively $2.611,2.597$, and 2.631, which are more than 1.0. The stability coefficient of red mud stockpile under the rainfall condition II is the minimum, indicating that the rainfall intensity has larger influence on the security and stability of stockpile. The reason is that the particle size of Bayer red mud is small and its permeability is poor, the infiltration of rainwater is difficult under the conditions of long but low intensity rainfall, and the influence on the stability of the slope is relatively small. While under the condition of short-term but heavy rainfall, rainfall intensity is greater than red mud permeability coefficient, and rainwater infiltration forms a transient saturation area on the surface of red mud or even surface runoff, the surface pore water pressure fluctuate greatly, resulting in the decrease of stability of the slope. According to relevant provisions of Technical Code for Geotechnical Engineering of Tailings Stacking Dam (GB50547-2010) [23], the minimum stability coefficient of antisliding stability of secondary reservoir dam 


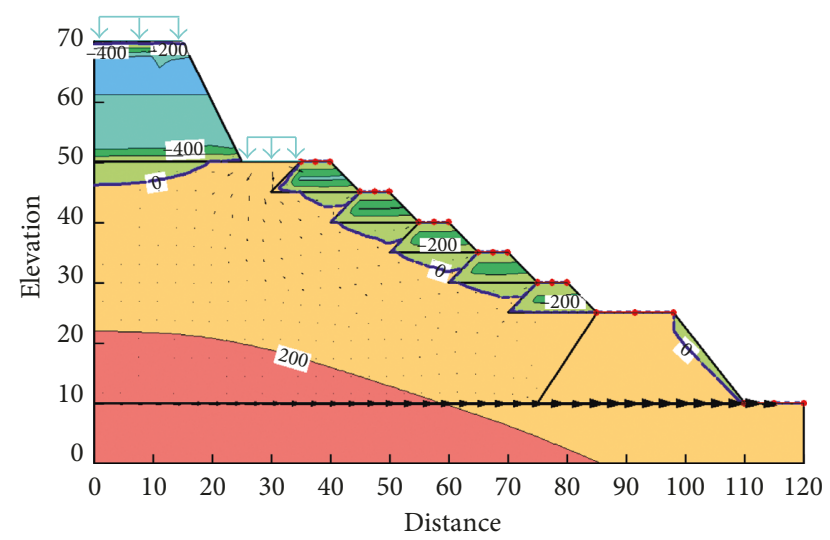

(a)

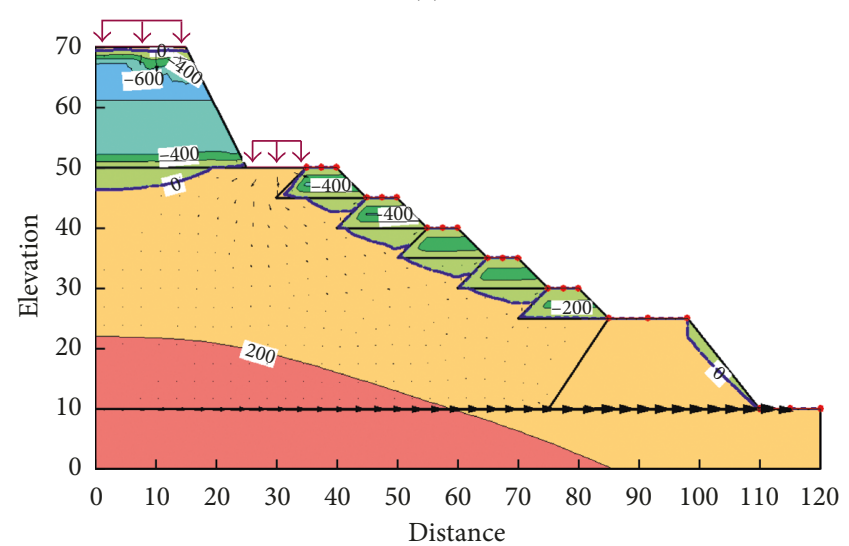

(b)

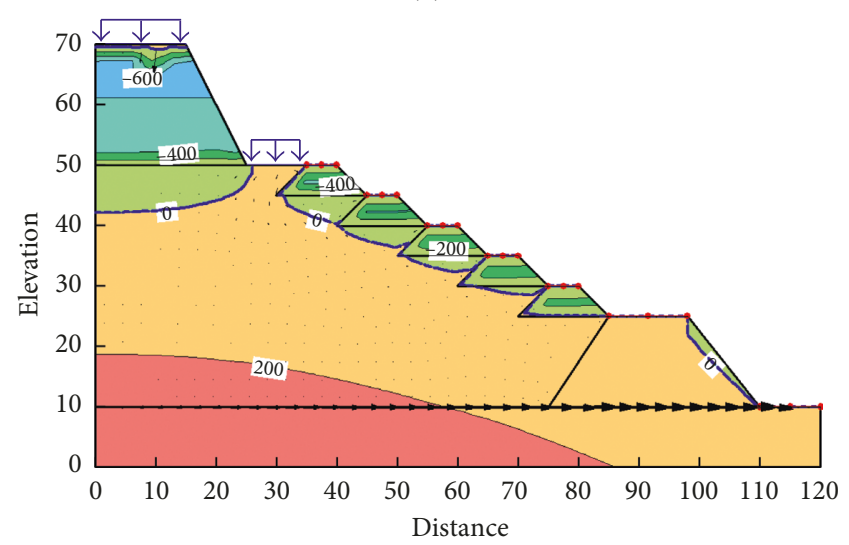

(c)

FIgURE 10: Pore water pressure distribution of red mud stockpile seepage field under different rainfall conditions: (a) rainfall condition I, (b) rainfall condition II, and (c) rainfall condition III.

should not be less than 1.25 during the normal running. In full consideration to actual rainfall conditions of red mud stockpile and on the basis of amplification to a certain extent, the stability coefficients of red mud stockpiles under three extreme rainfall conditions are more than 1.25 and are in the stable state. Therefore, the dilatation scheme of damming by the sintering red mud with good engineering quality for the Bayer red mud stockpiling proposed in Chapter 2 is feasible.

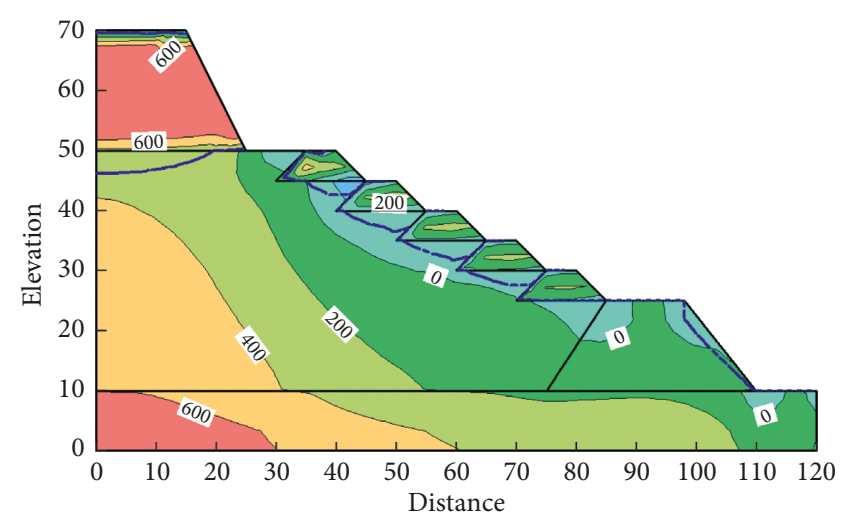

(a)

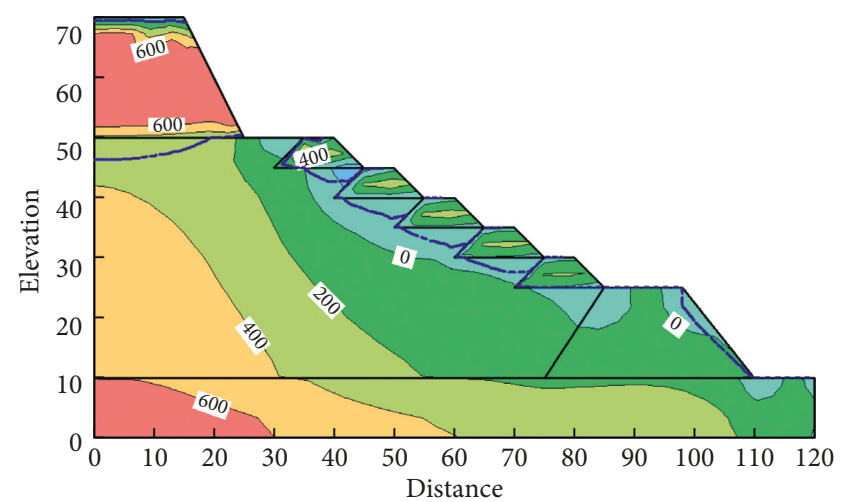

(b)

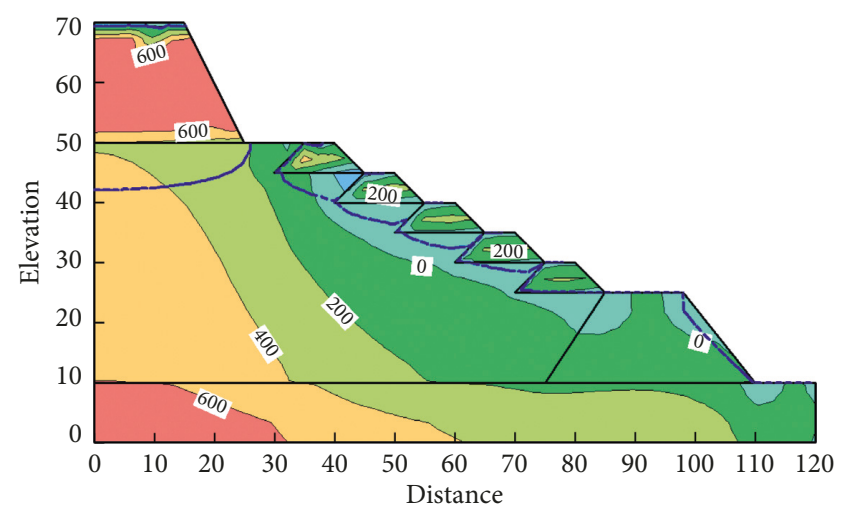

(c)

Figure 11: Vertical and effective stress distribution of red mud stockpile under different rainfall conditions: (a) rainfall condition I, (b) rainfall condition II, and (c) rainfall condition III.

\section{Conclusions}

At present, in case of failing to develop and utilize the red mud materials in quantity, how to dilate by the existing stockpiles and ensure the stability of stockpiles after dilatation is very important. Through a series of laboratory tests for three different kinds of red mud (sintering red mud, Bayer red mud from wetting process, and Bayer red mud from drying process), it is revealed that the red mud produced by different technologies has bigger differences in physical and mechanical properties. The intensity of 


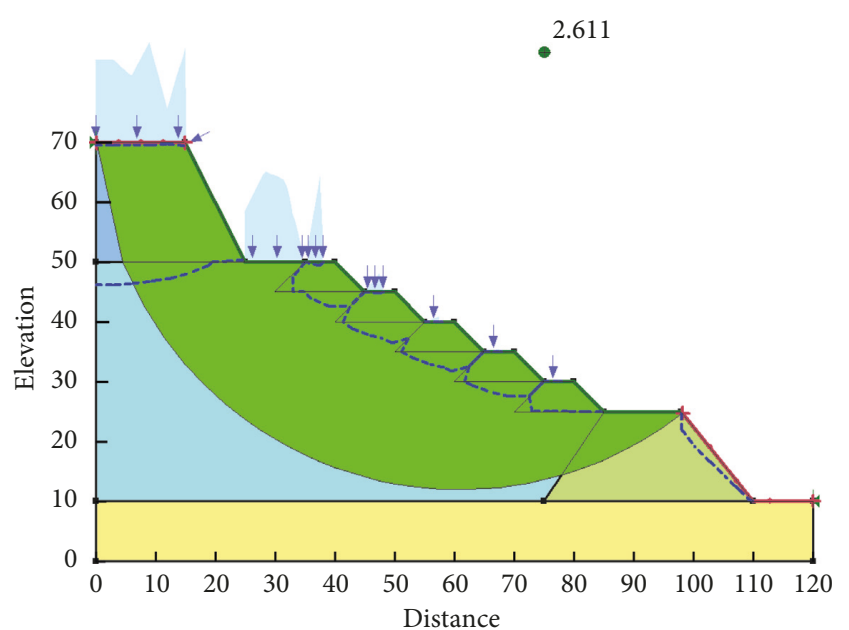

(a)

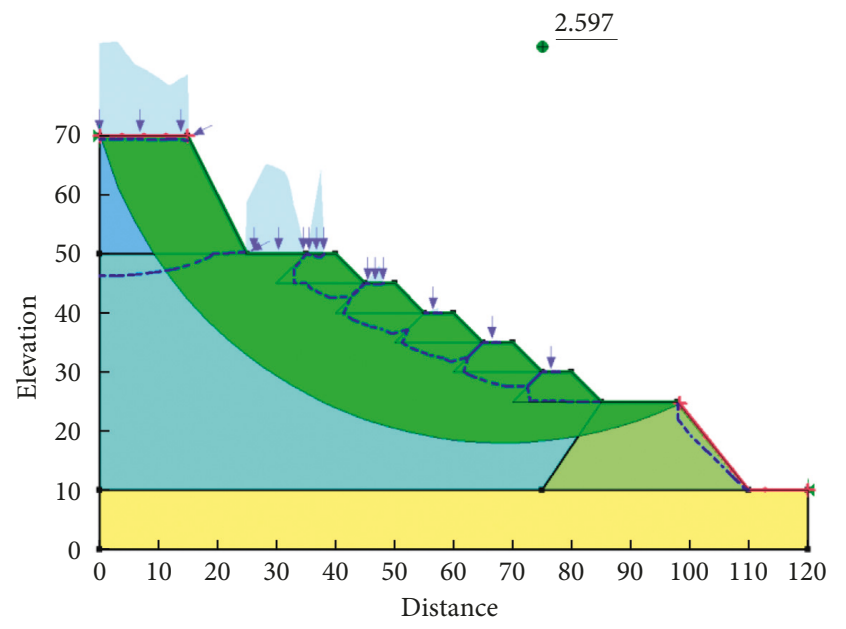

(b)

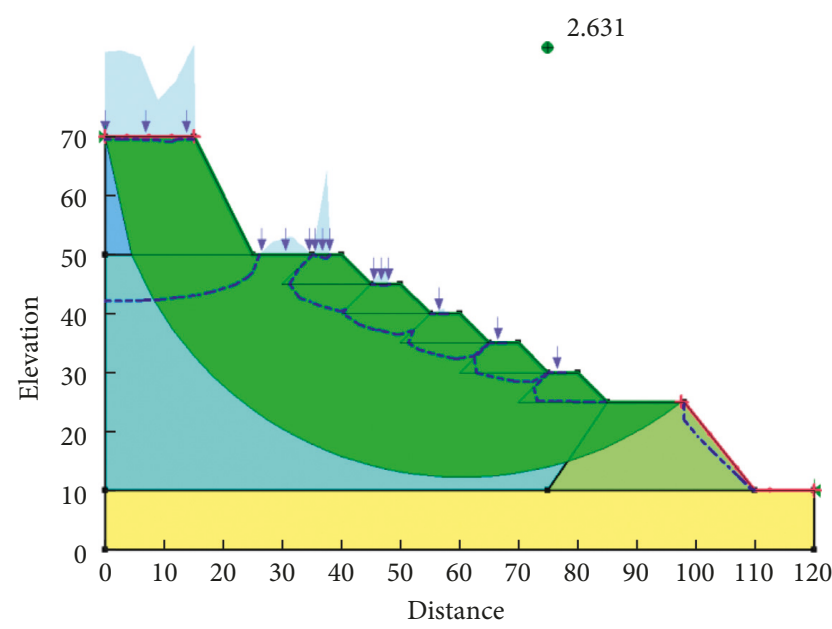

(c)

FIGURE 12: Stability coefficient of red mud stockpile under different rainfall conditions: (a) rainfall condition I, (b) rainfall condition II, and (c) rainfall condition III.

sintering red mud is much higher than that of Bayer red mud, and the sensitivity of sintering red mud to rainfall is lower than that of Bayer red mud. The sintering red mud can be used as the subdam of stockpile, to reduce the risk of collapse and dam break. The stability calculation results of red mud stockpiles under three extreme rainfall conditions by Geo-Studio show that the stockpile dilatation scheme proposed in this paper is feasible, to provide some reference for similar engineering.

\section{Data Availability}

The analyzed and generated data used to support the findings of this study are currently under embargo while the research findings are commercialized. Requests for data, 6/12 months after publication of this article, will be considered by the corresponding author.

\section{Conflicts of Interest}

The authors declare that there and no conflicts of interest regarding the publication of this paper.

\section{Acknowledgments}

This work was financially supported by the National Natural Science Foundation of China (no. 41602301), the Science and Technology Research Program of Chongqing Education Commission of China (no. KJ1601130), and the Foundation for High-level Talents of Chongqing University of Art and Sciences (no. R2015JJ07).

\section{References}

[1] G. Power, M. Gräfe, and C. Klauber, "Bauxite residue issues: I. Current management, disposal and storage practices," $\mathrm{Hy}$ drometallurgy, vol. 108, no. 1-2, pp. 33-45, 2011.

[2] X.-L. Nan, T.-A. Zhang, Y. Liu, and X.-L. Jiang, "Main categories of red mud and its environmental impacts," The Chinese Journal of Process Engineering, vol. 9, no. 1, pp. 459-464, 2009, in Chinese.

[3] N. Chang, X. M. Liu, H. H. Sun, and L. Li, "Pozzolanic behaviour of compound-activated red mud-coal gangue mixture," Cement and Concrete Research, vol. 41, no. 3, pp. 270-278, 2011.

[4] Y. J. Liu, N. Ravi, and H. Ming, "Red mud as an amendment for pollutants in solid and liquid phases," Geoderma, vol. 163, no. 1-2, pp. 1-12, 2011.

[5] Y. Qu and B. Lian, "Bioleaching of rare earth and radioactive elements from red mud using Penicillium tricolor RM-10," Bioresource Technology, vol. 136, pp. 16-23, 2013.

[6] S. Kumar, R. Kumar, and P. A. Bando, "Innovative methodologies for the utilization of wastes from metallurgical and allied industries," Resources, Conservation and Recycling, vol. 48, no. 4, pp. 301-314, 2006.

[7] P. Wang and D. Y. Liu, "Physical and chemical properties of sintering red mud and Bayer red mud and the implications for beneficial utilization," Materials, vol. 5, no. 10, pp. 1800-1810, 2012.

[8] Y. Liu, C. X. Lin, and Y. G. Wu, "Characterization of red mud derived from a combined Bayer process and bauxite calcination method," Journal of Hazardous Materials, vol. 146, no. 1-2, pp. 255-261, 2007. 
[9] V. Kumar, B. D. Nautiyal, and A. K. Jha, "Use of neutralized red mud in concrete," The Indian Concrete Journal, vol. 4, pp. 505-507, 1989.

[10] R. J. Chandler and G. Tosatti, "The Stava tailings dams failure," Geotechnical Engineering, vol. 113, no. 2, pp. 67-69, 1995.

[11] S. Moxon, "Failing again," International Water Power and Dam Construction, vol. 51, no. 5, pp. 116-211, 1999.

[12] R. A. Shakesby and J. R. Whitlow, "Failure of a mine waste dump in Zimbabwe: causes and consequences," Environmental Geology and Water Sciences, vol. 18, no. 2, pp. 1431531, 1991.

[13] C. Strachan, "Tailings dam performance from USCOD incident survey data," Mining Engineering, vol. 53, no. 3, pp. 49-53, 2001.

[14] K. M. Azizli, T. C. Yau, and J. Birrel, "Design of the Lohan tailings dam, Mamut Copper Mining Sdn. Bhd., Malaysia," Minerals Engineering, vol. 8, no. 6, pp. 705-712, 1995.

[15] H. Rahardjo, T. T. Lee, E. C. Leong, and R. B. Rezaur, "Response of a residual soil slope to rainfall," Canadian Geotechnical Journal, vol. 42, no. 2, pp. 340-351, 2005.

[16] J. M. Gasmo, H. Rahardjo, and E. C. Leong, "Infiltration effects on stability of a residual soil slope," Computers and Geotechnics, vol. 26, no. 2, pp. 145-165, 2000.

[17] M. J. Luo and C. Y. Dong, "An analysis of stability of Taimagou red mud stockpiling dam gradient," Nonferrous Metals Engineering \& Research, vol. 28, no. 6, pp. 5-12, 2007, in Chinese.

[18] Ministry of Housing and Urban-Rural Construction of the People's Republic of China, JGJ/T87-2012, Technical Specification for Engineering Geological Prospecting and Sampling of Constructions, China Architecture \& Building Press, Beijing, China, 2012, in Chinese.

[19] Y. B. Feng, D. Y. Liu, D. S. Li, and Q. Zhao, "A study on microstructure composition of unsaturated red mud and its impact on hydraulic characteristics," Geotechnical and Geological Engineering, vol. 35, no. 4, pp. 1357-1367, 2017.

[20] Ministry of Water Resources of the People's Republic of China, GB/T 50123, Standard for Soil Test Method, China Planning Press, Beijing, China, 1999, in Chinese.

[21] State Bureau of Technical Supervision, GB/T 16399, Method for Chemical Analysis of Clay, China Standards Press, Beijing, China, 1996, in Chinese.

[22] L. Hou, Research on the Mechanism of Pore Water Action within Unsaturated Soil and the Corresponding Slope Stability, Chongqing University, Chongqing, 2012, in Chinese.

[23] Ministry of Housing and Urban-Rural Construction of the People's Republic of China \& General Administration of Quality Supervision, Inspection and Quarantine of the People's Republic of China, GB 50547, Technical Code for Geotechnical Engineering of Tailings Embankment, China Planning Press, Beijing, China, 2010, in Chinese. 


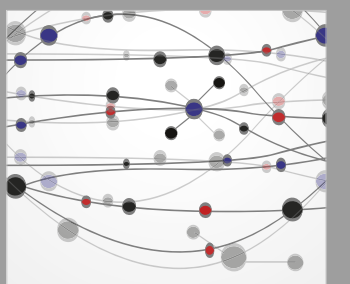

The Scientific World Journal
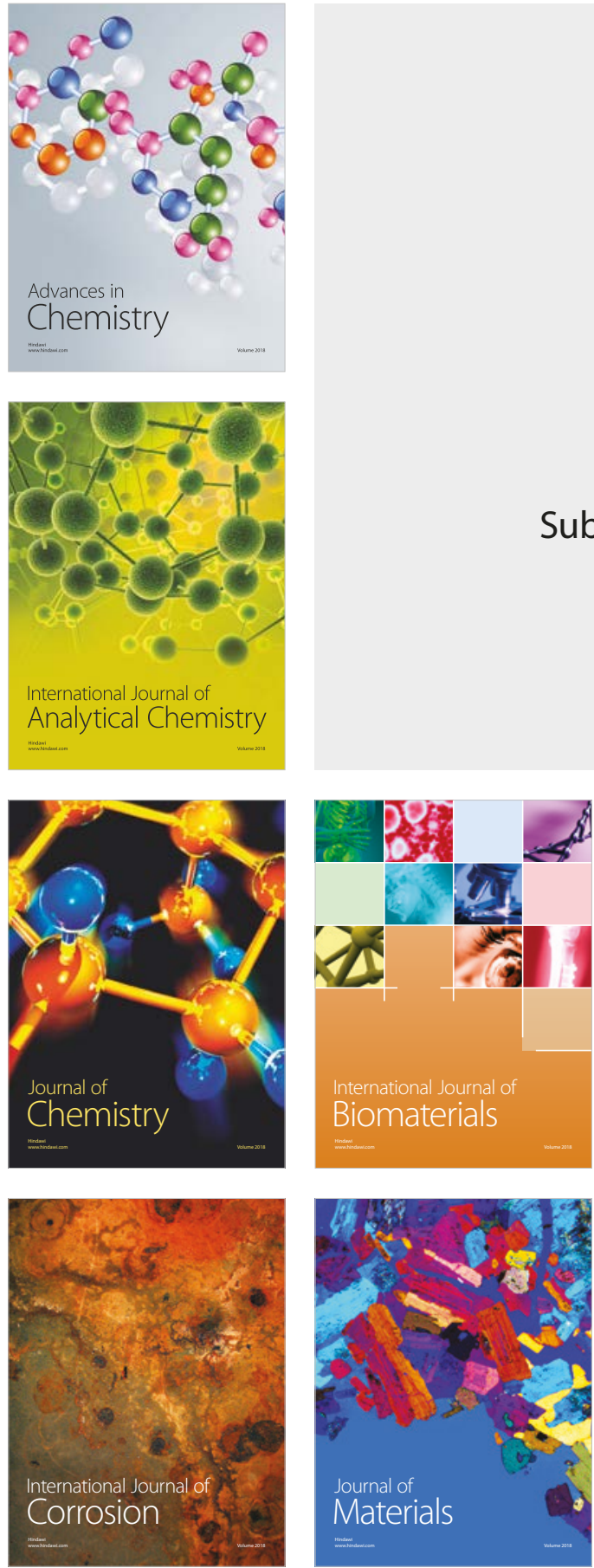

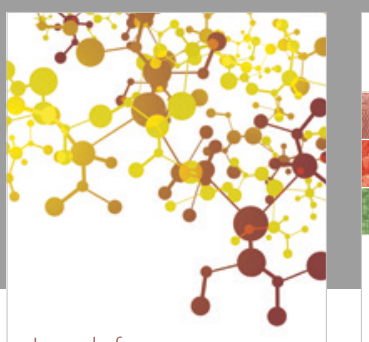

Journal of

Applied Chemistry
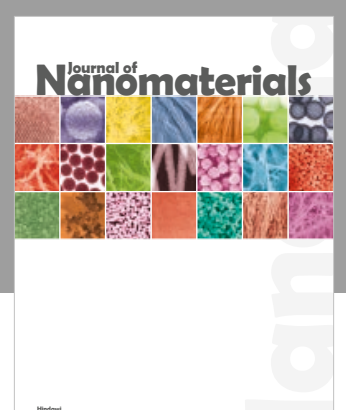

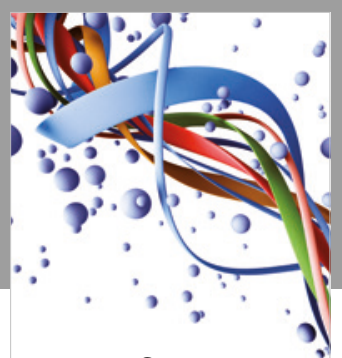

Scientifica

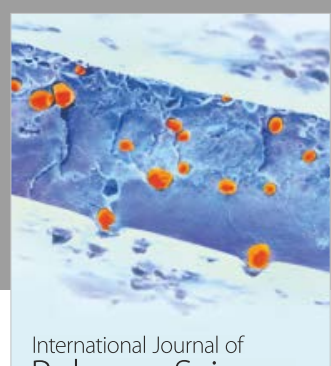

Polymer Science

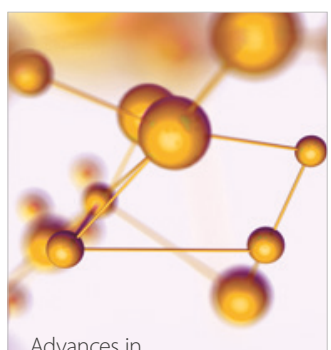

Physical Chemistry
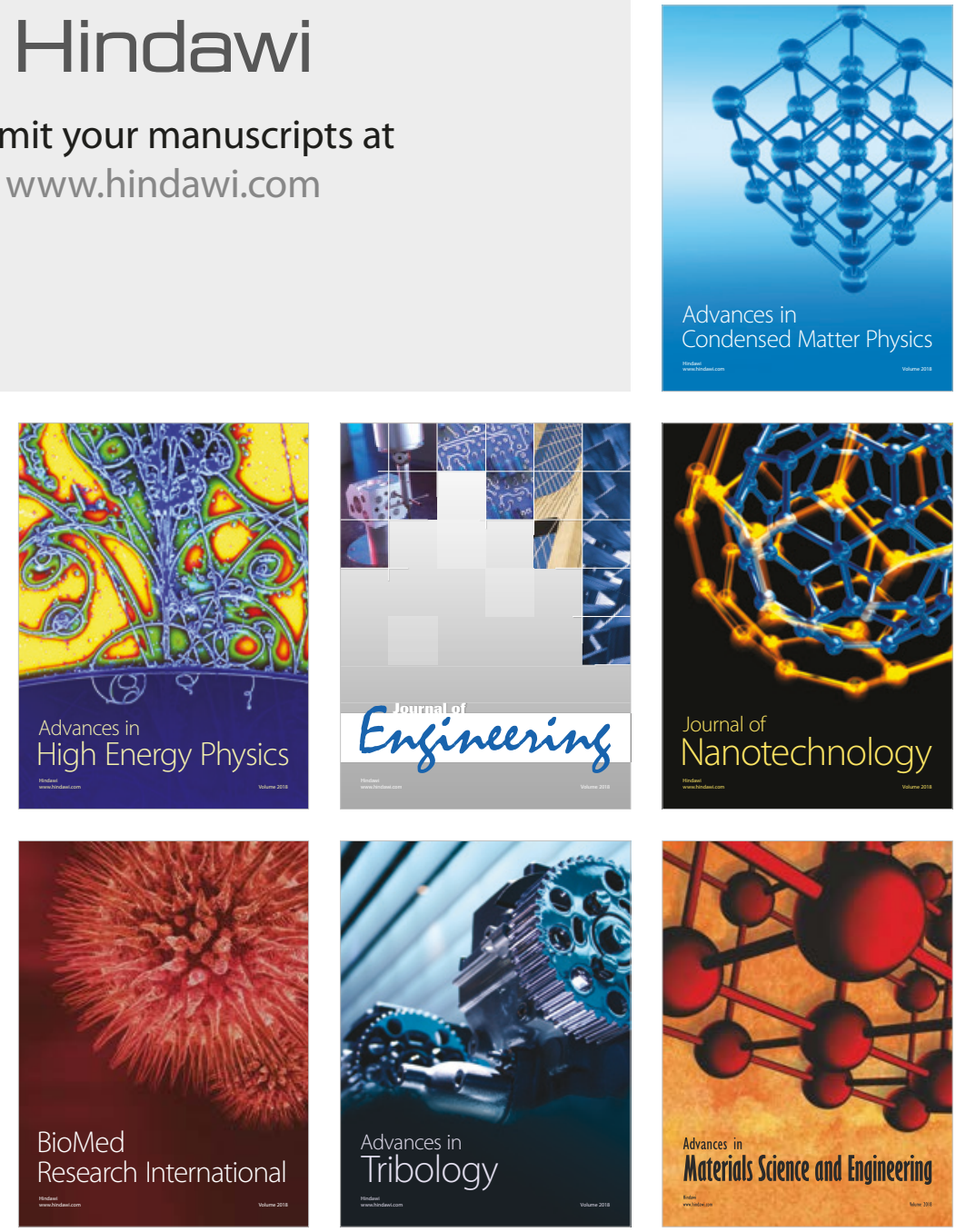